\title{
Combination of Iron Chloride and Polyacrylamide as Coagulant-Flocculants to Remove Pollutants in Dye Wastewater
}

\author{
Siti Aisyah Ishak ${ }^{1}$, Mohamad Fared Murshed ${ }^{1,3,4}$ *, Norli Ismail ${ }^{2,3}$, Siti \\ Norfariha Md Nasir ${ }^{2}$, Nurul Nadiah Mohd Azmi ${ }^{1}$
}

${ }^{1}$ School of Civil Engineering,

Universiti Sains Malaysia, 14300 Pulau Pinang, MALAYSIA

${ }^{2}$ School of Industrial Technology,

Universiti Sains Malaysia, 11800 Pulau Pinang, MALAYSIA

${ }^{3}$ Cluster of Solid Waste Management, Engineering Campus,

University Sains Malaysia, 14300 Pulau Pinang, MALAYSIA

${ }^{4}$ Cluster of Water Security, Engineering Campus,

University Sains Malaysia, 14300 Pulau Pinang, MALAYSIA

*Corresponding Author

DOI: https://doi.org/10.30880/ijie.2019.11.01.009

Received 30 April 2018; Accepted 27 September 2018; Available online 05 May 2019

\begin{abstract}
Dye Industrial developments have been increasing over the years and have created various environmental problems for water resources. This study was carried out in order to reduce the concentration of colour as well as the COD concentration by coagulation (Iron chloride) and flocculation (Polyacrylamide) using a standard jar test apparatus. The coagulation and flocculation processes were completed using Response Surface Methodology - Central Composite Design in order to see the effect of $\mathrm{pH}$ on iron chloride and polyacrylamide at optimum conditions. The analysis of zeta potential was done at various $\mathrm{pH}$ levels to compare the reduction of COD and colourant at various levels. Further analysis using the sludge produced included measuring for phytotoxicity using Lactuca sativa seeds. The treatment showed the highest colour removal with $95 \%$ (31 pt. co) and $92.0 \%$ (42 $\mathrm{mg} / \mathrm{L}$ ) COD reduction at $\mathrm{pH}$ conditions of around $5.4,375 \mathrm{mg} / \mathrm{L}$ of coagulant and $28 \mathrm{mg} / \mathrm{L}$ of flocculant. Charge neutralization occurred when the $\mathrm{pH}$ moved to acidic region of 4-6. It was found that $\mathrm{pH}$ significantly influenced Iron chloride and Polyacrylamide for both responses (colour and COD). The phytotoxicity assessment indicated the mortality rate is increased with an increase in sludge concentration. Results revealed that $\mathrm{FeCl}_{3} \mathrm{PAM}$ at $100 \%$ undiluted dye sludge recorded the highest mortality rate.
\end{abstract}

Keywords: Colour, COD, coagulation-flocculation, zeta potential, Lactuca sativa

\section{Introduction}

Large quantities of dyes are currently being used in fabric and textile industries. High concentrations of COD (150$10000 \mathrm{mg} / \mathrm{L}$ ) and colours (50- $2500 \mathrm{pt}$. co) are released in the effluent as the end product [1]. Therefore, it is a compulsory for the fabric and textile industry to undergo wastewater treatment as either a physical, chemical or biological process to maintain the quality of water as stated by Environmental Quality Act 1974 (Act 127). Concerns 
about wastewater treatment are becoming more and more prevalent and it is essential that researchers find a better approach.

Coagulation is a process whereby chemical coagulant (inorganic or organic polymer) are used to remove particle compounds in the wastewater. The most widely used coagulants are aluminium sulfate (also known as Alum), and iron sulphate or iron chloride; this is due to their cheap price, effective performance and ability to produce large amounts of sludge [2]. The addition of cationic charge enables neutralization of the solution by attaching onto the surface of negative charge particles to form micro floc particles [3]. Coagulant with trivalent ions are more efficient than those with divalent ions due to the amount of unoccupied charges [4]. Furthermore, the addition of flocculants (coagulant aids) contributes to an increased efficiency by promoting the destabilization of particles to form micro-floc [5]. Following the addition of flocculants, micro floc particles will bind onto more than one particle and will need to be removed by sedimentation and filtration [6].

Generally, the coagulants and flocculants used are mineral nutrients including metal salts like aluminium sulphate, ferric chloride and synthetic flocculants which are often acrylamide based. Thereby, impacts on the environment may include the increase of metal concentrations and sludge production. The usage of flocculants in the treatment may assist in reducing the amount of coagulant used. However, the performance of mineral salts used in the coagulationflocculation treatment will depend on the $\mathrm{pH}$ of the water; therefore, an optimum $\mathrm{pH}$ range should be determined. The $\mathrm{pH}$ condition of the wastewater plays a vital role since it can influence other factors.

Therefore, this study focused more on the effect of $\mathrm{pH}$ on other factors such as coagulant and flocculant doses. Despite the treatment of wastewater, the process of identifying pollutants in the sludge after treatment is crucial for environmentalists to prevent the production of pollutants from industries. Sludge formed after wastewater treatment processes was investigated in previous studies as stabilizer for contaminated soil, as substitute material in construction, as fertilizer in agriculture/horticulture and others potential aspects [7]. The application of sludge waste is recommended as an alternative for soil fertilization. The benefits include minimal costs, increases in soil organic matter content, soil microbial activity, soil fertility and a decrease in the overall quantity of sludge [8]. Great challenges are faced by researchers in utilizing the sludge produced either for soil fertilizer, compost, or to be extracted back to reuse the material for the industry.

\section{Methodology}

Dye wastewater was treated using the coagulation and flocculation process based on central composite design (CCD), this was done to minimize the number of experiments required. The responses included in this study relate to colour and COD reduction.

\subsection{Samples Collection of Dye Wastewater}

Dye wastewater was collected six times from the fabric industry in Penang to obtain an average reading. It was then preserved by acidifying to $\mathrm{pH}<2$ with concentrated $\mathrm{H}_{2} \mathrm{SO}_{4}$ [9].

\subsection{Determination of COD and Colour}

The chemical oxygen demand (COD) of the samples was determined using the Closed Reflux Method 5220D) for wastewater analysis [9]. Readings for colour unit and concentration of COD were taken using HACH Spechtrophotomer DR 2800 [9]. Method No. 2120C reported in Platinum-cobalt (pt. co) was used for colour determination [9]. The removal efficiency of colour was obtained using the following formula.

$$
\text { Re moval }(\%)=(I-F) / I * 100
$$

where: $I$ is initial colour concentration of textile wastewater treated effluent, $F$ is final colour concentration of textile wastewater treated effluent.

\subsection{Coagulation and Flocculation Procedure}

A standard jar-test appliance equipped with 6 stainless steel paddles and a stirrer was used for the coagulation and flocculation tests to see the removal of colour and COD. A volume of $1 \mathrm{~L}$ effluent of dye wastewater was transferred into the jar before the wastewater $\mathrm{pH}$ was adjusted with $1 \mathrm{M} \mathrm{NaOH}$ and $1 \mathrm{M} \mathrm{H}_{2} \mathrm{SO}_{4}$. The sample was rapidly mixed at $150 \mathrm{rpm}$ following the addition of iron chloride. The rapid mixing continued for $3 \mathrm{~min}$. Polyacrylamide was then added to the samples at a slow speed for $15 \mathrm{~min}$ at $45 \mathrm{rpm}$ before waiting $30 \mathrm{~min}$ for settlement. Samples of supernatant were taken to measure COD, colour and pH using the American Public Health Association (APHA) method [9]. 


\subsection{Measurement of Zeta Potential}

The zeta potential was determined according to Zeta sizer Nano ZS (Malvern). The supernatant was injected into a capillary cell using a syringe for both zeta potential measurements. All experimental runs were performed at $25^{\circ} \mathrm{C}$ and analyses were made in triplicates. The Henry equation was applied by measuring the electrophoretic mobility to calculate the reading of zeta potential [10]:

$$
U_{E}=\frac{2 \varepsilon z f(k a)}{3 \eta}
$$

where: $U_{E}$ is electrophoretic mobility, $\varepsilon$ is the permittivity of the dielectric medium, $\eta$ is dynamic viscosity, and $f(k a)$ is the Henry correction factor. Here $k$ is the reciprocal double layer thickness calculated based on the ionic strength of the coagulated system. While, $a$ is the radius of the particles measured by the Zeta sizer.

\subsection{Statistical Analysis}

The process was analyzed by utilizing the Response Surface Methodology (RSM) using central composite design (CCD) to see the effect of iron chloride and polyacrylamide doses at different ranges of $\mathrm{pH}$. RSM is a set of mathematical and statistical tools that is useful for modelling and predicting the response of interest according to different factors with a target of obtaining the optimization of the studies [11]. Central composite design (CCD) was applied to specify the relationships between $\mathrm{pH}$ and other factors (coagulant and flocculant) on measured responses (COD and colour reduction). There were twenty experimental runs undertaken with three different factors: $\mathrm{pH}$, coagulant dose and flocculant dose. All the experiments were replicated three times. Table 1 shows the condition for coagulation and flocculation treatment for both responses. Each numeric factor was set at five levels, six axial points (plus and minus alpha), eight factorials point (plus and minus one), and six center point for pure error evaluation with three blocks as shown in Table 2. Analysis of the effects of interaction between independent variables, coefficients, standard deviation and others was conducted using Design Expert 6.0.2 software. The Analysis of Variance (ANOVA) was measured using p-value $95 \%$ confidence level.

Table 1 - Central composite design (CCD) for coagulation/ flocculation treatment

\begin{tabular}{llllll}
\hline Factor & \multicolumn{5}{c}{ Level } \\
\cline { 2 - 6 } & $\mathbf{- \alpha}$ & $\mathbf{- 1}$ & $\mathbf{0}$ & $\mathbf{+ 1}$ & $\boldsymbol{\alpha}$ \\
\hline pH & 1.10 & 3 & 6 & 9 & 10.90 \\
Coagulant Dose & 105.05 & 200 & 350 & 500 & 594.95 \\
Flocculant Dose & 10.50 & 20 & 35 & 50 & 59.49 \\
\hline
\end{tabular}

\subsection{Assessment of Phytotoxicity}

The assessment of sludge dye residual after each treatment using a combination of $\mathrm{FeCl}_{3}$ and $\mathrm{PAM}, \mathrm{FeCl}_{3}, \mathrm{PAM}$ and control (dye wastewater) were further analyzed for phytotoxicity using seed germination test with lettuce seed (Lactuca sativa) as proposed by OECD [12]. Lettuce seeds (20 seeds) at five different ratios (1\%, 3\%, 10\%, 30\% and $100 \%$ ), and sludge produced: nutritive solutions were experimented in triplicate. A nutritive solution was comprised of a mixture of $\mathrm{NaHCO} 3, \mathrm{MgSO} 4, \mathrm{CaSO} 4.2 \mathrm{H} 2 \mathrm{O}$ and $\mathrm{KCl}$ and dissolved in distilled water. The mixture of salts required aging time before it could be applied. Each petri plate contained twenty seeds and filtration type paper, these were germinated in the incubator for five days at $22+2{ }^{\circ} \mathrm{C}$ constant temperature. Measurements of Lethal concentration, LC50 was followed with Trimmed Spearman-Karber Method [13] at a $95 \%$ confidence interval. Note the equation of Absolute germination, AG and Germination index, GI as follows in Eq. 3 and Eq. 4:

$$
\begin{gathered}
A G=\frac{N(g)}{N(s)} \\
G I=\frac{N(g)}{N(s)}\left(\frac{R L(g)}{R L(c)}\right)
\end{gathered}
$$

where: $N(g)$ is total number of seeds, $N(s)$ is average number of germinated seeds in the sludge produced with presence of nutritive solution, $N(c)$ is average number of germinated control seeds in the nutritive solution, $R L(g)$ is average root length of germinated seed in the sludge produced with addition of nutritive solution, $R L(c)$ is average root length of germinated seed in the nutritive solution. 


\section{Results and Discussion}

The dye wastewater effluent produced recordings at $\mathrm{pH}$ 10.6-12.0, COD range of 420 - $700 \mathrm{mg} / \mathrm{L}$, temperature 38 $-40{ }^{\circ} \mathrm{C}$, BOD range of $45-60 \mathrm{mg} / \mathrm{L}$, zeta potential $-35.34 \mathrm{mV}$ and Colour range up to 745 colour units. Disperse dye, reactive dye and vat dye were the main dyes used in the factory. According to the Environmental Quality Act (1974), the standard limit for dye wastewater effluent is a COD value of $250 \mathrm{mg} / \mathrm{L}$, BOD value of $50 \mathrm{mg} / \mathrm{L}$ and Colour range up to 200 colour units. Therefore, the discharge of dye wastewater should be treated before being released into the river.

The analysis of optimization was carried out using quadratic model and the results of Analysis of Variance (ANOVA) for individual factors and interaction between the factors are tabulated in Table 3 for both responses (colour and COD reduction). The $\mathrm{r}^{2}$ values for colour removals of dye wastewater was 0.9239 ; meanwhile, $\mathrm{r}^{2}$ values for COD reduction showed 0.9219 respectively. This indicates that $0.91-0.95$ of the total variation can be explained by the empirical models; however, the range $0.05-0.01$ remains unexplained. The values of the coefficient of determination were satisfactory since $r^{2}$ were close to 1 . Regression analysis of colour and COD reduction showed the significance of each coefficient determined using p-value at a significance level of 0.05. Based on Table 2, the larger significant effect has a smaller number of p-values at $95 \%$ confidence level. From here, both responses showed pH is significantly influenced by coagulant dose (Iron chloride) and flocculant dose (polyacrylamide).

This suggests that increasing the dosage and $\mathrm{pH}$ may cause a reduction in colour and COD content. The coagulation and flocculation process of colour and COD reduction showed similar significant effects based on p-value $<0.05$ only to the interaction of the quadratic term of $\mathrm{pH}\left(\mathrm{pH}^{2}\right)$, the quadratic term of coagulant dose $\left(\mathrm{Coagulant}\right.$ dose $\left.\mathrm{C}^{2}\right)$, the interaction effect of $\mathrm{pH}^{*}$ Coagulant dose and the interaction effect of $\mathrm{pH}^{*}$ Flocculant dose. Lack of fit test for both reduction was not significant ( $\mathrm{p}$-value $>0.05$ ) which indicates that the models were in good condition. As can be seen, this treatment shows the highest order of colour and COD reduction. The highest removal is recorded at $99 \%$ for both colour and COD reduction with $6 \mathrm{Pt}$. Co and $5 \mathrm{mg} / \mathrm{L}$, respectively remaining. The relationship between two responses (colour removal and COD reduction) and three selected quantitative variables ( $\mathrm{pH}$, coagulant dose and flocculant dose) was approximated using he second order model. The set of second order models is given in terms of coded variables as shown in the Eq. 5 and Eq. 6.

Colour removal:

$$
93.90+1.56 x_{1}+3.34 x_{2}-1.54 x_{3}-10.31 x_{1}^{2}-7.69 x_{2}^{2}-3.00 x_{3}^{2}-5.75 x_{1} x_{2}+14.50 x_{1} x_{3}+3.50 x_{2}
$$

COD reduction:

$$
93.71+1.71 x_{1}+0.71 x_{2}-0.76 x_{3}-13.64 x_{1}^{2}-8.39 x_{2}^{2}-2.02 x_{3}^{2}-6.25 x_{1} x_{2}+8.25 x_{1} x_{3}-2.25 x_{2} x_{3}
$$

Table 2 - p-values for colour and COD reduction

\begin{tabular}{lcc}
\hline & \multicolumn{2}{c}{ p-values (95 \% Confidence level) } \\
\cline { 2 - 3 } \multicolumn{1}{c}{ Source of variance } & Colour Reduction & COD Reduction \\
\hline Model & 0.0014 & 0.0015 \\
$\mathrm{pH}$ & 0.4178 & 0.3723 \\
Coagulant dose & 0.1057 & 0.7058 \\
Flocculant dose & 0.4257 & 0.6865 \\
pH $^{2}$ & 0.0005 & 0.0001 \\
Coagulant dose & & 0.0017 \\
Flocculant dose $^{2}$ & 0.0031 & 0.3003 \\
pH $^{*}$ Coagulant dose & 0.1417 & $\underline{0.0284}$ \\
pH $^{*}$ Flocculant dose & $\underline{0.0411}$ & $\underline{0.0078}$ \\
Coagulant dose ${ }^{*}$ Flocculant dose & $\underline{0.0003}$ & 0.3649 \\
Lack of fit & 0.1771 & 0.3531 \\
\hline
\end{tabular}


Table 3 - Analysis of variance (ANOVA) for colour and COD reduction

\begin{tabular}{|c|c|c|c|c|c|}
\hline No & $\mathbf{X}_{1}: \mathbf{p H}$ & $\begin{array}{c}\mathrm{X}_{2}: \text { Coagulant dose } \\
\mathrm{mg} / \mathrm{L}\end{array}$ & $\begin{array}{c}\mathbf{X}_{3} \text { : Flocculant dose } \\
\mathrm{mg} / \mathrm{L}\end{array}$ & $\begin{array}{l}\text { Response 1: COD } \\
\text { reduction \% }\end{array}$ & $\begin{array}{l}\text { Response 2: } \\
\text { Colour } \\
\text { reduction \% }\end{array}$ \\
\hline 1 & 1 & 1 & -1 & 66 & 87 \\
\hline 2 & 0 & 0 & 0 & 87 & 92 \\
\hline 3 & -1 & 1 & 1 & 70 & 80 \\
\hline 4 & 0 & 0 & 0 & 58 & 60 \\
\hline 5 & 1 & -1 & 1 & 92 & 98 \\
\hline 6 & -1 & -1 & -1 & 94 & 96 \\
\hline 7 & 0 & 0 & 0 & 56 & 44 \\
\hline 8 & 0 & 0 & 0 & 60 & 61 \\
\hline 9 & -1 & -1 & 1 & 85 & 93 \\
\hline 10 & 1 & 1 & 1 & 72 & 89 \\
\hline 11 & 1 & -1 & -1 & 92 & 97 \\
\hline 12 & -1 & 1 & -1 & 98 & 89 \\
\hline 13 & 0 & 0 & $-\alpha$ & 51 & 54 \\
\hline 14 & 0 & $-\alpha$ & 0 & 65 & 68 \\
\hline 15 & $-\alpha$ & 0 & 0 & 74 & 66 \\
\hline 16 & 0 & 0 & 0 & 70 & 70 \\
\hline 17 & 0 & $\alpha$ & 0 & 97 & 88 \\
\hline 18 & 0 & 0 & $\mathrm{~A}$ & 81 & 73 \\
\hline 19 & 0 & 0 & 0 & 99 & 99 \\
\hline 20 & A & 0 & 0 & 87 & 85 \\
\hline
\end{tabular}

As reported in the ANOVA, the interaction effects between $\mathrm{pH}$ and coagulant dose are shown to be significant for both responses. Fig. 1 shows a diagram of three-dimensional display of response surface plot for: a) Colour and b) $\mathrm{COD}$ reduction for interaction between $\mathrm{pH}$ and coagulant dose. The diagrams depicted in Fig. 1 can be distinguished by the maximum stationary point. The highest rate of colour and COD removal was increased by an increase in $\mathrm{pH}$ and coagulant dosage. Acidic conditions supply more $\mathrm{H}^{+}$after the addition of cationic charge from metal salts to achieve destabilisation, binding with negative colloids results in charge neutralization. Similar results from previous studies also show a high reduction of golden yellow dye at lower $\mathrm{pH}$ values due to conversions of solubilised particles to nonsolubilised particles; this then forms the non-ionized structure [14]. Trivalent cation such as $\mathrm{Al}^{3+}$ or $\mathrm{Fe}^{3+}$ showed highest efficiency compared to lower charges $\left(\mathrm{Ca}^{2+}, \mathrm{Mg}^{2+}\right.$ or $\left.\mathrm{Na}^{+}\right)$. Besides, the measured zeta potential observed more charge density at an acidic $\mathrm{pH}$ compared to alkaline conditions (See Fig. 2). This result supports a higher reduction for both responses. Charge density was more negative when the $\mathrm{pH}$ was adjusted above $\mathrm{pH} 9$.

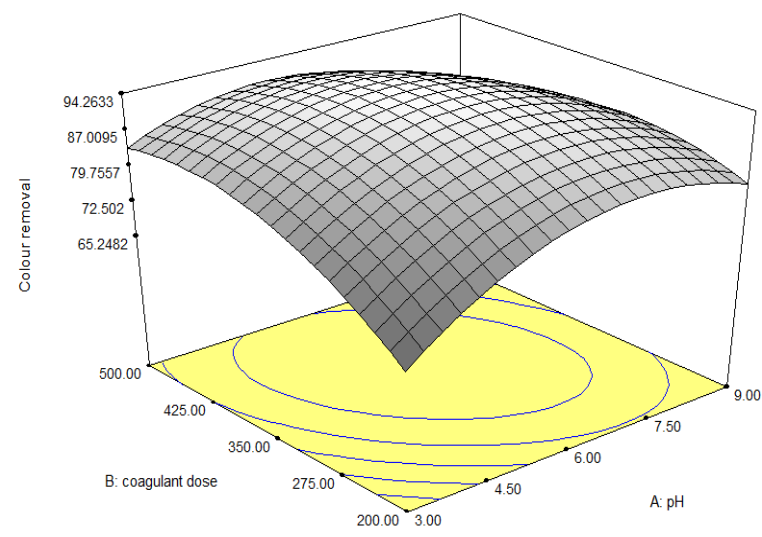

a)

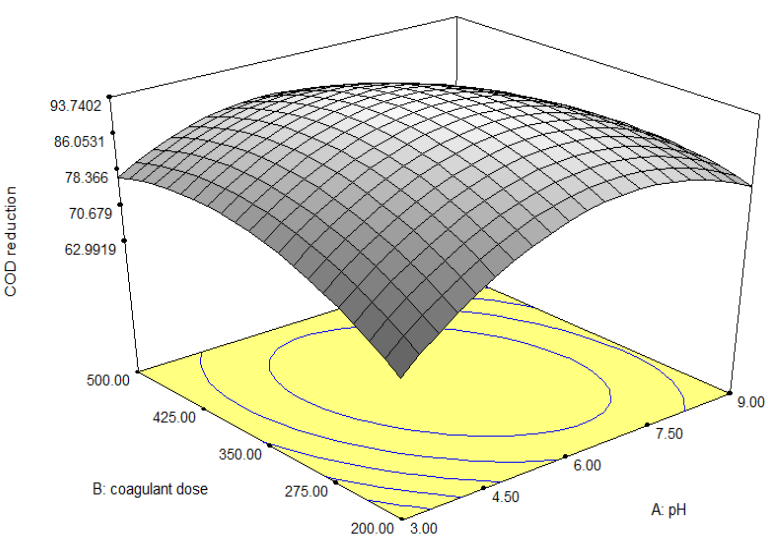

b)

Fig. 1 - Response surface plot a) Colour and b) COD reduction for the interaction between pH and iron chloride

Numerous works claim that $\mathrm{pH}$ is the most crucial parameter in water and wastewater treatment [15]. The presence of multivalent metal ions such as iron $\left(\mathrm{Fe}^{3+}\right)$ as coagulants in wastewater can hydrolyse and specifically attach themselves to the negatively charged dyes. Particles of iron are strongly hydrolysed in the aqueous solution and surrounded by six co-ordinated molecules of water in octahedral form [16]. When the central metal ion carries a high positive charge, $\mathrm{O}-\mathrm{H}$ bonds are polarised and more hydroxylated compound are created. The anionic dye bearing 
sulfonic groups, is electrostatically attracted by the cationic coagulant [17]. Hydrolysis reactions take place when the charge neutralization in negatively charged colloids by coagulant (cation) occurs in the wastewater. Iron salts release cationic hydrolysis products $\left(\mathrm{Fe}(\mathrm{OH})^{3+}\right)$ which lead to the adsorption of the negatively charged dye particles for destabilization [18].

Fig. 2 shows the zeta potential of the $375 \mathrm{mg} / \mathrm{L}$ dosage at different level of $\mathrm{pH}(\mathrm{pH} 3-\mathrm{pH} 11)$. In the acid region, the zeta potential of iron chloride increased from $\mathrm{pH} 3$ until pH 5 before the trend decreased dramatically with the increased $\mathrm{pH}$. The order of percentage reduction of colour and COD was consistent with the zeta potential shown in Fig. 2. As pH increased further, the zeta potential reached $45 \mathrm{mV}$ and then dropped back near to zero charge at pH 9. The increase in zeta potential illustrates the increase in electrostatic repulsion between particle-particles which is successful in stopping the attraction and collision between particles due to Brownian motion [19]. It is observed that the maximal reduction for both responses was achieved when the zeta potential was positive. As $\mathrm{pH}$ further increased, the zeta potential became negative and the colour and COD reduction decreased due to the re-stabilization of particles. Minimal zeta potential of the particles explains the lack of electrostatic repulsion between particles to outweigh the attraction force between particles, therefore contributing to a low reduction percentage.

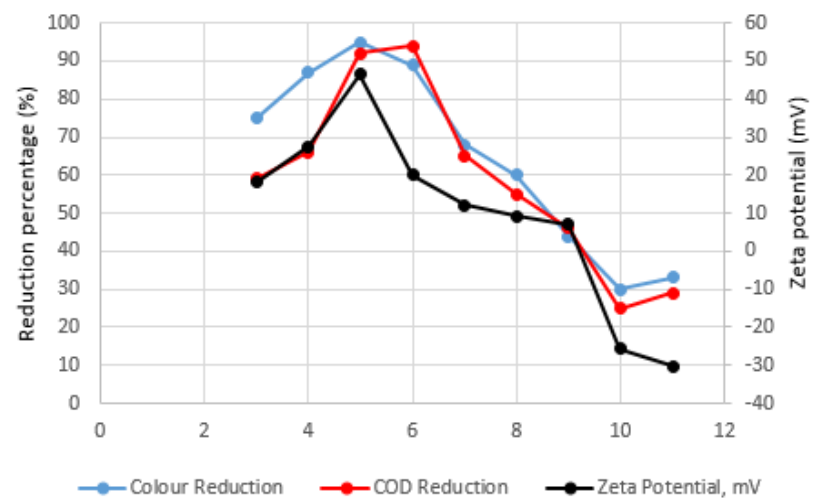

Fig. 2 - The effect of different pH values on the reduction of COD, colour and zeta potential with addition of Iron chloride $(375 \mathrm{mg} / \mathrm{L})$

Surface complexation is the main mechanism at a lower iron doses. Negative particles are able to adsorb with the presence of cations which produces the precipitate of metal salt with the constituent ions [20] and the formation of surface hydroxide occurs as a consequence. As the coagulant increases, the complex surfaces and the precipitates also increase until they becomes saturated. Following this, large amounts of precipitate formed.

However, when $\mathrm{pH}$ and coagulant were increased beyond the optimum value, a decrease in percentage reduction of colour and COD can occur due to overdosing the reaction solution. Overdosing deteriorates supernatant quality, with reference to the "re-stabilization" of the colloidal particles. Thus, the particles cannot be coagulated. These circumstances decrease coagulation rates, therefore problems arise in the water treatment process. Since the optimum coagulant dosage is crucial, the dosage amount needs to be controlled by adjusting $\mathrm{pH}$ at specific conditions to achieve the highest reduction percentage. Meanwhile, the interaction effect between $\mathrm{pH}$ and flocculant dose was analysed in the three-dimensional display of response surface plot as shown in Fig. 3.

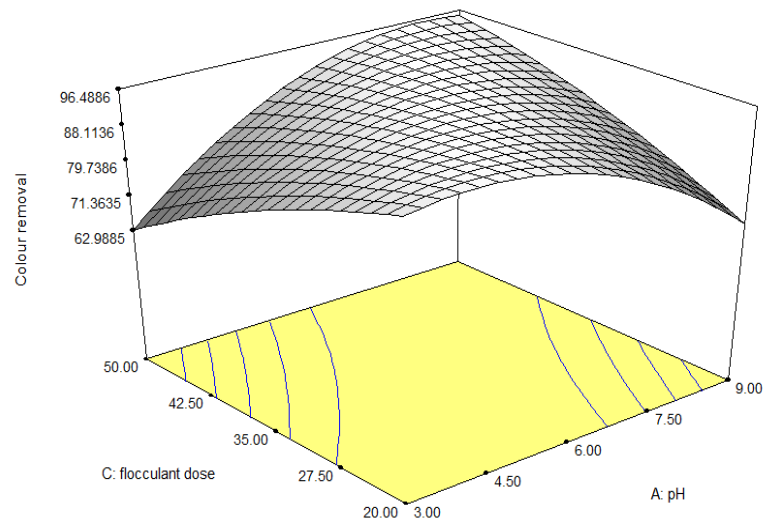

a)

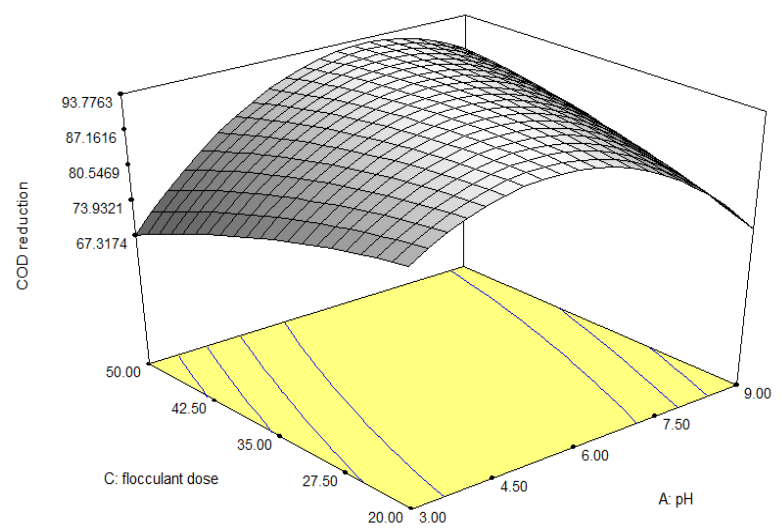

b)

Fig. 3 - Response surface plot a) Colour and b) COD reduction for the interaction between pH and polyacrylamide. 
Based on the optimum values of colour and COD reduction, the interaction of $\mathrm{pH}$ and flocculant dose demonstrates a non-proportional relationship. With the increase in $\mathrm{pH}$ value, the flocculant dose must be lower in order to get the highest removal efficacy. When the particle surface and PAM molecules have a suitable hydrogen bonding site, this may be adequate to cause adsorption between the dye hydroxyl -OH group which forms hydrogen bond with amide groups $-\mathrm{NH}_{2}$ of PAM. At a higher $\mathrm{pH}$, the concentration of $\mathrm{OH}^{-}$is high, providing an opportunity for more amide group to attach. Meanwhile, a lower $\mathrm{pH}$ provides a surface layer with highest concentration of $\mathrm{H}^{+}$so the adsorption only occurs between the hydrogen bond. The bridging mechanism is strengthened by the effect of PAM (synthetic organic flocculant) since it has a high molecular weight. Thus, the flocculation effect becomes greater. The study explained the effectiveness using acrylamide was due to formation of bigger flocs and thus speed up the settling time [21]. Higher molecular weight is attributed to higher potential bridging effect; thus, increasing the flocculating activity [22]. Another study found that increasing chain length from a polymer with a higher molecular weight provides a good flocculation process. This is because of the numerous binding sites which providing the ability to attach onto the surface [23]. Bridging flocculants are required to adsorb strongly onto the particles and have the abilities to provide a gap between the particles [24]. In any case, if excessive polymer is added to the suspension, the particles can easily re-stabilized due to surface saturation or steric stabilization.

Finally, three different conditions were randomly tested from the optimized results for the validation experiments. The results of the selected $\mathrm{pH}$, coagulant dosage and flocculant dosage given in the combined treatments of iron chloride and PAM as tabulated in Table 4. Actual and predicted values for COD and colour reduction are included.

Table 4 - Validation test for colour removal and COD reduction

\begin{tabular}{ccccccc}
\hline pH & CD & FD & \multicolumn{2}{c}{ Colour reduction } & \multicolumn{2}{c}{ COD reduction } \\
\cline { 3 - 6 } & & & Actual & Predicted & Actual & Predicted \\
\hline 5.4 & 375 & 28.0 & 95.0 & 94.8 & 92.0 & 93.7 \\
5.4 & 374 & 29.0 & 93.4 & 94.0 & 90.2 & 93.0 \\
4.8 & 369 & 23.6 & 90.1 & 92.0 & 87.9 & 90.0 \\
\hline
\end{tabular}

$* \mathrm{CD}=$ coagulant dose $; \mathrm{FD}=$ Flocculant dose

Further analysis of the sludge produced by both iron chloride and PAM was taken into account for phytotoxicity evaluation using dye sludge. Plant bioassays demonstrated in Table 5 showed the percentage mortality of dye sludge using different types of coagulant, flocculant and dye wastewater (known as toxicant). Effects on Lactuca sativa seeds can be seen at five different ratios starting including $1 \%, 3 \%, 10 \%, 30 \%$ and $100 \%$ using the previous optimum coagulation process (pH: 5.4; Coagulant Dose: $375 \mathrm{mg} / \mathrm{L}$ and Flocculant Dose: $28 \mathrm{mg} / \mathrm{L}$ ). Referring to the germination and root growth of Lactuca sativa seeds as absolute germination, AG and germination index, GI. The phytotoxicity assessment revealed LC50 values which means the mortality rate at fifty percent of dye sludge.

Table 5 - Set of experimental assay data mortality percentage by using different types of toxicant

\begin{tabular}{cccccc}
\hline Seeds & \multicolumn{3}{c}{ 20 seeds for each ratio } \\
\hline $\begin{array}{c}\text { Types of toxicant/ Ratio } \\
\text { of control solution }\end{array}$ & $\mathbf{1 \%}$ & $\mathbf{3 \%}$ & $\mathbf{1 0 \%}$ & $\mathbf{3 0 \%}$ & $\mathbf{1 0 0 \%}$ \\
\hline FeCl3+PAM & 55 & 60 & 65 & 70 & 80 \\
FeCl3 & 50 & 50 & 55 & 65 & 75 \\
PAM & 45 & 45 & 55 & 60 & 65 \\
Dye wastewater (control) & 50 & 50 & 55 & 65 & 70 \\
\hline
\end{tabular}

Approximately $80 \%$ of the total seeds (20 seeds) showed the germination of Lactuca sativa seeds as the control experiment. Results indicated the mortality rate is increased proportional to the increase in dye sludge concentration. Lactuca sativa seed in the sludge after the treatment with toxicant of $\mathrm{FeCl}_{3} \mathrm{PAM}$ at $100 \%$ undiluted dye sludge recorded the highest mortality rate with only $20 \%$ of the seeds surviving this condition. The heavy metal residual can affect germination since seed growth is very sensitive [25], the existence of iron and acrylamide monomers could possibly affect growth rates. Weak concentrations of sludge toxicant produced (1-10\%) had no significant adverse effect on the germination index (see Table 5). However, the untreated dye wastewater (control) seemed to affect the growth of the roots. Therefore, GI of the control is quite high even at low concentration levels; this can be concluded due to the presence of high level of nutrients in dye wastewater. 
The root was recorded as the sensitive part of the seed rather than the shoot [26]. Calculated LC50 values (see Table 6) for sludge toxicant produced after treatment with $\mathrm{FeCl}_{3}-\mathrm{PAM}<\mathrm{FeCl}_{3}<\mathrm{PAM}$ is shown in increasing order. Similar results of LC50 were produced by the toxicant of $\mathrm{FeCl} 3$ and dye wastewater. The phytotoxicity assessment revealed that, LC50 close to 1 contained high values of toxic substances. Sludge toxicant using PAM was demonstrated as the least toxic with LC50: 19 while the germination using $\mathrm{FeCl}_{3}-\mathrm{PAM}$ was close to $1 \%$. These findings indicate the acrylamide monomers also affected the germination test. Metal ions ( $\mathrm{Sn}, \mathrm{Cr}(\mathrm{III}), \mathrm{Cr}(\mathrm{VI}), \mathrm{Fe}$ and etc.), organic substances (contain aromatic hydrocarbon) and non-metallic pollutants (boron, cyanide and fluoride) were classified as pollutants which affected the germination [27]. Table 6 shows the radical length and root length were calculated and represented as AG and GI. The presence of soluble toxic compounds greatly inhibited the phytotoxicity assessment. Other external factors such as seed quality, hormonal, genetic, chromatin development and environmental factors were reported to have an impact on seed germination.

Table 6 - Various toxicant used for AG, GI and LC50 values.

\begin{tabular}{|c|c|c|c|c|c|c|c|c|c|c|}
\hline \multirow{3}{*}{$\begin{array}{c}\text { Types } \\
\text { of } \\
\text { toxicant/ } / \mathrm{LC}_{50}\end{array}$} & \multicolumn{10}{|c|}{ \% Sludge solution mixed to control solution } \\
\hline & \multicolumn{2}{|c|}{$1 \%$} & \multicolumn{2}{|c|}{$3 \%$} & \multicolumn{2}{|c|}{$10 \%$} & \multicolumn{2}{|c|}{$30 \%$} & \multicolumn{2}{|c|}{$100 \%$} \\
\hline & AG & GI & AG & GI & $\mathbf{A G}$ & GI & $\mathbf{A G}$ & GI & $\mathbf{A G}$ & GI \\
\hline $\mathrm{FeCl} 3+\mathrm{PAM} / 3$ & 45 & 36 & 40 & 28 & 44 & 24 & 38 & 15 & 25 & 7 \\
\hline $\mathrm{FeCl} 3 / 12$ & 50 & 34 & 50 & 30 & 45 & 27 & 35 & 17 & 25 & 7 \\
\hline PAM/ 19 & 55 & 47 & 55 & 50 & 45 & 43 & 40 & 29 & 35 & 12 \\
\hline $\begin{array}{c}\text { Dye ww (control)/ } \\
12\end{array}$ & 50 & 18 & 50 & 15 & 45 & 13 & 35 & 10 & 30 & 8 \\
\hline
\end{tabular}

\section{Summary}

The application of Response Surface Methodology - Central Composite Design in the treatment enables to see 99\% achievement of colour and COD reduction in dye wastewater at minimum experimental runs. Both response surface designs used the highest order polynomial which is quadratic, whereby the significant p-value is less than 0.05 . The interaction effects of $\mathrm{pH}$ were found to be significant between iron chloride and polyacrylamide which indicates that $\mathrm{pH}$ plays a crucial role in the coagulation and flocculation process. Supportive evidence by zeta potential measurement showed a reduction in charge density from acidic to basic regions. Additional findings on the phytotoxicity assessment were explored for collected sludge residues through seed germination tests. Lactuca sativa was chosen as a plant seed; the phytotoxicity test was done by reporting percentage mortality, AG and GI of sludge from various treatments such as $\mathrm{FeCl}_{3}$ and $\mathrm{PAM}, \mathrm{FeCl}_{3}, \mathrm{PAM}$ and dye wastewater as control. The mortality rate of Lactuca sativa seeds start to increase with an increase in the concentration of sludge toxicant.

\section{Acknowledgment}

The authors would like to acknowledge the financial support from MyBrain15 for PhD scholarship and RUI grant no. 1001/PAWAM/814259. Authors wish to thank Universiti Sains Malaysia for providing the lab facilities in which the experiments were conducted.

\section{References}

[1] Fajardo, A. S., Martins, R. C., Silva, D. R., Martínez-Huitle, C. A. and Quinta-Ferreira, R. M. (2017). Dye wastewaters treatment using batch and recirculation flow electrocoagulation systems, Journal of Electroanalytical Chemistry, 801, 30-37.

[2] Abidin, Z. Z., Madehi, N. and Yunus, R. (2017). Coagulative behaviour of jatropha curcas and its performance in wastewater treatment. Environmental Progress and Sustainable Energy, 36(6), 1709-1718.

[3] Ho, Y. C., Norli, I., Abbas Alkarkhi, F. M. and Morad, N. (2010). Characterization of biopolymeric flocculant (pectin) and organic synthetic flocculant (PAM): A comparative study on treatment and optimization in kaolin suspension. Bioresource Technology, 101, 1166-1174.

[4] Eom, W., Park, H., Noh, S. H., Koh, K. H., Lee, K., Lee, W. J. and Han, T. H. (2017). Strengthening and stiffening graphene oxide fiber with trivalent metal ion binders. Particle and Particle Systems Characterization, 34(9), 1-6. 
[5] Nidheesh, P. V., Thomas, P., Nair, K. A., Joju, J., Aswathy, P., Jinisha, R. and Gandhimathi, R. (2017). Potential use of Hibiscus rosa-sinensis leaf extract for the destabilization of turbid water. Water, Air, and Soil Pollution, 228(1), 51.

[6] Saritha, V., Srinivas, N. and Vuppala, N. S. (2017). Analysis and optimization of coagulation and flocculation process. Applied Water Science, 7(1), 451-460.

[7] Rakotonimaro, T. V., Neculita, C. M., Bussière, B., Benzaazoua, M. and Zagury, G. J. (2017). Recovery and reuse of sludge from active and passive treatment of mine drainage-impacted waters: a review. Environmental Science and Pollution Research, 24(1), 73-91.

[8] Arif, M. S., Riaz, M., Shahzad, S. M., Yasmeen, T., Ashraf, M., Siddique, M. and Buttler, A. (2018). Fresh and composted industrial sludge restore soil functions in surface soil of degraded agricultural land. Science of the Total Environment, 619, 517-527.

[9] APHA (2005). Standard methods for the examination of water and wastewater American Public Health Association/American Water Works Association/Water Environment Federation. Washington.

[10] Wang, Y., Duan, J., Liu, S., Li, W. Leeuwen, J. and Mulcahy, D. (2014). Removal of As (III) and As (V) by ferric salts coagulation - Implications of particle size and zeta potential of precipitates. Separation and Purification Technology, 135, 64-71.

[11] Montgomery. D. C. (2005). Design and analysis of experiments. New York: Wiley.

[12] Organisation for Economic Co-operation and Development (2006). OECD guidelines for the testing of chemicals / section 2: Effects on biotic systems test no. 208: Terrestrial plant test: Seedling emergence and seedling growth test. Paris: OECD Publishing, Paris.

[13] Hamilton, M. A., Russo, R. C. and Thurston, R. V. (1977). Trimmed Spearman-Karber method for estimating median lethal concentrations in toxicity bioassays. Environmental Science and Technology, 11, 714-719.

[14] Xiao, X., Sun, Y., Sun, W., Shen, H., Zheng, H., Xu, Y., Zhao, J., Wu, H. and Liu, C., (2017). Advanced treatment of actual textile dye wastewater by Fenton-flocculation process, The Canadian Journal of Chemical Engineering, 95, 1245-1252.

[15] Irfan, M., Butt, T., Imtiaz, N., Abbas, N., Khan, R.A. and Shafique, A. (2017). The removal of COD, TSS and colour of black liquor by coagulation-flocculation process at optimized $\mathrm{pH}$, settling and dosing rate. Arab Journal of Chemistry, 10, 2307-2318.

[16] Jiao, R., Fabris, R., Chow, C. W. K., Drikas, M., van Leeuwen, J., Wang, D. and Xu, Z. (2017). Influence of coagulation mechanisms and floc formation on filterability. Journal of Environmental Sciences (China), 57, 338345.

[17] Hadi, A. G., Humedy, E. H., Saddam, N. S. and Abd-Alameer, F. S. (2016). Spectrophotometric study of complex formation between hematoxylin and $\mathrm{Al3}+$ and Fe3+ ions. International Journal of PharmTech Research, 9, 292298.

[18] Kanmani, P., Aravind, J., Kamaraj, M., Sureshbabu, J. and Karthikeyan, S. (2017). Environmental applications of chitosan and cellulosic biopolymers: A comprehensive outlook. Bioresource Technology, 242, 295-303.

[19] Rodrigues, C. S. D., Madeira, L. M. and Boaventura, R. A. R. (2017). Synthetic textile wastewaters treatment by coagulation/flocculation using ferric salt as coagulant. Environmental Engineering and Management Journal, 16, 1881-1889.

[20] Koh, J. (2011). Dyeing with disperse dyes. In Textile Dyeing. London: InTech.

[21]Zhang, Z., Wang, J., Liu, D., Li, J., Wang, X., Song, B., Yue, B., Zhao, K. and Song, K. (2017). Hydrolysis of polyaluminum chloride prior to coagulation: Effects on coagulation behavior and implications for improving coagulation performance. Journal of Environmental Sciences, 57, 162-169.

[22] Rodriguez-Narvaez, O. M., Peralta-Hernandez, J. M., Goonetilleke, A. and Bandala, E. R. (2017). Treatment technologies for emerging contaminants in water: A review. Chemical Engineering Journal, 323, 361-380.

[23]Zahrim, A. Y., Dexter, Z. D., Collin, J. G. and Hilal, N. (2017). Effective coagulation-flocculation treatment of highly polluted palm oil mill biogas plant wastewater using dual coagulants: Decolourisation, kinetics and phytotoxicity studies. Journal of Water Process Engineering,16, 258-269.

[24] Finch, C. A. (1983). Chemistry and technology of water-soluble polymers. New York: Springer.

[25] Jaouani, K., Karmous, I., Ostrowski, M., El Ferjani, E., Jakubowska, A. and Chaoui, A. (2018). Cadmium effects on embryo growth of pea seeds during germination: Investigation of the mechanisms of interference of the heavy metal with protein mobilization-related factors. Journal of Plant Physiology, 226, 64-76.

[26] Siti Aisyah, I., Siti Norfariha, M. N., Megat Azlan, M. A. and Norli, I. (2014). comparison of synthetic and natural organic polymers as flocculant for textile wastewater treatment. Iranica Journal of Energy and Environment, 5 (3), 436-445

[27] Priac, A., Badot, P. M. and Crini, G. (2017). Treated wastewater phytotoxicity assessment using Lactuca sativa: Focus on germination and root elongation test parameters. Comptes Rendus Biologies, 340(3), 188-194. 